\title{
Os sentidos da metrópole: balanço conceitual com base nas publicações dos Cadernos Metrópole
}

\author{
Senses of the metropolis: a conceptual balance \\ based on publications of Cadernos Metrópole
}

Olga Lucia Castreghini de Freitas-Firkowski [l]

Patricia Baliski [II]

\begin{abstract}
Resumo
0 propósito deste texto é contribuir com a compreensão de como a metrópole e a metropolização têm sido abordadas conceitualmente nos textos publicados no periódico científico Cadernos Metrópole. Isso porque, além de ele ser um dos periódicos especializados nessa temática, completa, em 2019, duas décadas de ininterrupta publicação, abrangendo exatamente o período em que tais objetos readquirem um destacado vigor conceitual. Inicialmente, realizou-se um levantamento de cunho bibliométrico, identificando os conceitos mais utilizados nos textos publicados, o que foi complementado pela leitura dos textos e pela busca de referências da matriz teórico-conceitual que os orientou.

Palavras-chave: metrópole; metropolização; bibliometria; matriz teórico-conceitual; Cadernos Metrópole.
\end{abstract}

\begin{abstract}
The purpose of this text is to contribute to the understanding of how the metropolis and metropolization have been conceptually approached in the articles published in the scientific journal Cadernos Metrópole. This journal specializes in the metropolitan theme and has been published for two decades, without interruption, covering exactly the period in which this object regained a marked conceptual vigor. Initially, a bibliometric survey was carried out to identify the concepts most used in the published texts. This was complemented by the reading of the texts, searching for references of the theoreticalconceptual matrix that guided them.
\end{abstract}

Keywords: metropolis; metropolization; statistical bibliometrics; theoretical-conceptual matrix; Cadernos Metrópole. 
A metrópole tem sido objeto de investigação de pesquisadores de diversas áreas do conhecimento, em especial em razão das transformações pelas quais tem passado nas últimas décadas, tanto em relação à sua forma, quanto ao se protagonismo na sociedade atual. Tal protagonismo, no âmbito teórico, tem sido associado à relevância da dimensão espacial para a compreensão dos fenômenos que se colocam no mundo atual. Benko (2002, p. 51) já apontava que a metropolização se colocava como a expressão do processo de mundialização, na medida em que

o crescimento, a potência e a riqueza estão cada vez mais concentrados em um número limitado de grandes polos [...] o desenvolvimento das metrópoles é que puxa as economias. As trocas ocorrem menos entre as nações do que entre esses polos que tendem a organizar-se em redes $[\ldots]$.

Soja (2013, p. 138), por sua vez, afirma que tal protagonismo das metrópoles pode ser associado a uma "virada espacial", no sentido do reconhecimento e da difusão do pensamento espacial e de que os espaços urbanos "produzem uma força gerativa que seria a causa primordial do desenvolvimento econômico, da inovação tecnológica e da criatividade cultural", enfatizando o que denomina "causalidade espacial urbana", provocando uma reviravolta nos esquemas teóricos de interpretação da realidade atual.

A profusão de proposições teóricas que revisitam o conceito busca suas limitações e propõe novos termos também, o que é relevante, não apenas nos países em que o processo de metropolização ocorre de modo mais potente, como também naqueles em que a expressão socioespacial do fenômeno se dá em meio às profundas contradições da própria sociedade que o abriga. Assim, termos antigos, como megalópole (Lang e Knox, 2009; Lang e Dhavale, 2005), são revisitados e novos nexos propostos; termos novos são formulados, como metápolis (Ascher, 1995), cidade-região (Scott et al., 2001), exópolis e pós-metrópoles (Soja, 2000; 2013); termos que recuperam o conceito de região, mas que a ele atribuem uma perspectiva diferenciada, como megarregião (Sassen, 2007), são algumas das proposições que ganham destaque nas discussões acerca da metropolização e de como esse processo tem produzido novas expressões espaciais nas últimas décadas. Em tal contexto, pareceu-nos importante compreender a apreensão conceitual desse objeto no Brasil, sobretudo por considerar a diversidade de tendências e de áreas abrangidas nesse debate, além das tentativas de sua aproximação à realidade brasileira. Uma indagação recorrente refere-se à aderência de nossas análises, em um país que não está no centro do debate e da realidade metropolitana mundial, a esse conjunto de proposições, termos e perspectivas analíticas.

Dentre os diversos caminhos possíveis para contribuir com essa reflexão, optamos pela análise dos textos publicados na revista Cadernos Metrópole, em especial porque ela carrega em seu próprio nome a centralidade desse objeto, além do fato de completar, em 2019, duas décadas de ininterrupta publicação, abrangendo, de certo modo, exatamente o período em que tal objeto readquire um destacado vigor conceitual.

Editada desde 1999, a revista Cadernos Metrópole configura-se como um 
importante veículo de divulgação de pesquisas relacionadas às metrópoles, sob os mais distintos vieses. Com seus primeiros números dedicados à publicação dos resultados do Grupo de Pesquisa Pronex: "Metrópole, desigualdades socioespaciais e governança urbana: Rio de Janeiro, São Paulo e Belo Horizonte", 1 a revista, desde então, tem ampliado consideravelmente o escopo de autores e de suas respectivas filiações institucionais, sendo alguns, inclusive, de procedência estrangeira. 0 crescimento e a consolidação do periódico refletem-se nos 40 números publicados, que reúnem 406 artigos e 544 autores. $^{2}$

Nessas duas décadas de divulgação dos Cadernos Metrópole, as reflexões e os resultados apresentados indicam a pluralidade de perspectivas a partir das quais a temática metropolitana pode ser abordada. Resultado disso foi a publicação de artigos em forma de dossiês temáticos, tais como os que trouxeram discussões relativas a migração, trabalho e moradia, grandes projetos urbanos, território e região, cidadania, governança democrática, gestão metropolitana, cultura, dentre inúmeros outros. Embora sejam concepções e abordagens diferenciadas, a maioria dos artigos tem em comum o fato de dedicarem-se a determinadas questões a partir de uma espacialidade convergente, a metrópole.

Assim, motivou-nos compreender qual conteúdo conceitual está associado aos textos que têm a metrópole como objeto: há convergência entre o uso do termo e os sentidos que têm sido atribuídos à discussão recentemente? Há efetiva compreensão da distinção necessária, no Brasil, acerca de metrópole e da região metropolitana? 0 conceito é objeto de reflexão ou se refere a um consenso dado academicamente e, portanto, utilizado sem maiores aprofundamentos do sentido a ele atribuído? Ao tratar uma realidade objetiva, a metrópole limita-se a ser o continente dos processos que são analisados? Há preocupação com a delimitação do que se está denominando metrópole, se o aglomerado metropolitano, se a região metropolitana, se o município que abriga o nome atribuído à metrópole?

Por certo, tais questões não serão integralmente respondidas, mas foram elas que nos orientaram na busca de uma metodologia que conseguisse expressar um pouco dessas preocupações. Também não se trata de reavaliar trabalhos publicados e com mérito científico inquestionável, mas de lançar luz a essa nossa preocupação conceitual que está no cerne do avanço do campo científico e da interlocução com outros campos do saber e com a literatura internacional.

Dada a crescente complexidade das metrópoles e as imensas proporções que tais espacialidades têm alcançado nas últimas décadas, as novas denominações anteriormente apontadas estão presentes em vários artigos dos Cadernos Metrópole, indicando a atualização do debate em torno das grandes configurações urbano-metropolitanas contemporâneas. Além disso, entende-se como extremamente relevante o papel da revista para a discussão da temática relativa às regiões metropolitanas e ao próprio processo de metropolização no Brasil.

No entanto, se, de um lado, a publicação dos Cadernos Metrópole evidencia a vasta possibilidade de discussão da metrópole, de outro, chama a atenção para a necessidade da escoIha dos conceitos mais adequados diante da constelação de conceitos existentes. 
0 presente empreendimento analítico parte dessa reflexão inicial e tem como objetivo apontar alguns elementos que contribuam não somente para o debate sobre as metrópoles, mas que também indiquem qual tem sido a principal matriz teórico-analítica ou a árvore conceitual ${ }^{3}$ existente nos textos publicados nos Cadernos Metrópole ao longo dessas duas décadas. Para tanto, o texto divide-se em duas partes, além desta introdução e das considerações finais. Na primeira, é explicada a metodologia com a qual se procedeu à análise de todos os números da revista; e, na segunda, são indicados os resultados obtidos com a análise empreendida, bem como é apresentado o esboço da matriz teórico-conceitual que embasa o debate no âmbito do periódico.

\section{Bibliometria e análise conceitual: as metodologias utilizadas}

A ampliação do processo de metropolização tem repercutido na criação de espacialidades cada vez mais complexas e, por consequência, tem alterado a organização da sociedade que nelas vive cotidianamente. Tal situação tem suscitado o esforço dos vários campos do conhecimento, no sentido de trazer novos elementos explicativos para a realidade que se conforma. Assim, as teorias que explicavam o crescimento das metrópoles, na década de 1970, não contêm todos os elementos para compreendê-lo na atualidade. Ou, do mesmo modo, conceitos tiveram que ser construídos como meio de elucidar novos aspectos da realidade, antes inexistentes ou irrelevantes.
É, nesse sentido, que a produção intelectual reflete não somente as transformações pelas quais a sociedade passa e se configura, mas também se caracteriza como uma importante fonte de pesquisas para se examinar as mudanças ocorridas nos diversos campos do conhecimento. Afinal, os conceitos são socialmente construídos e portam os sentidos das realidades nas quais seu uso é demandado.

Nessa perspectiva, diversos trabalhos acadêmicos têm demonstrado a importância do levantamento da produção científica, tanto para avaliação, quanto como meio de identificar o procedimento dos pesquisadores em suas decisões na construção da ciência (Ultramari, Firmino e Silva, 2011; Leite Filho e Siqueira, 2007). Alguns desses estudos, pautados na análise bibliométrica, têm como metodologia o exame da atividade científica pelo estudo quantitativo das publicações. Pritchard (1969) aponta que a bibliometria pode se referir tanto ao estudo da literatura produzida sobre algum tema, como também às análises da concentração e/ou dispersão dos temas, realizadas por meio da mensuração do que foi veiculado em periódicos científicos ou livros.

Dentre os vários usos plausíveis desse tipo de análise, indicados por Silva (2004), destacam-se a possibilidade de determinar 0 crescimento de certas áreas de conhecimento da ciência, a produtividade dos autores ou instituições, a evolução cronológica da produção científica e o envelhecimento dos campos científicos.

A abordagem bibliométrica pode ser empreendida em distintas áreas do conhecimento e com diferentes objetivos. Daviet (2005) valeu-se de uma minuciosa análise dos textos publicados na revista francesa Annales de 
Géographie, para propor uma periodização em três momentos que caracterizaram a geografia industrial francesa entre os anos de 1970 e 1999. Ultramari, Firmino e Silva (2011) analisaram a produção sobre planejamento urbano no Brasil, tendo como fonte de pesquisa o banco de teses e dissertações da Capes (Coordenação de Aperfeiçoamento de Pessoal de Nível Superior). Leite Filho e Siqueira (2007) verificaram as principais características bibliométricas da Revista Contabilidade \& Finanças (USP), tendo como base todos os fascículos dessa publicação. Silva (2004) empregou a análise na produção científica docente do Programa de Pós-Graduação em Educação Especial da UFSCar, e Mendoza (2016), a partir das bases Web of Science e SCIELO, efetuou uma análise bibliométrica com vistas ao tema gentrificação.

Diferentemente dos exemplos citados, a análise realizada nos Cadernos Metrópole ateve-se somente aos artigos que explicitavam, nas palavras-chave, temas relacionados diretamente aos processos de urbanização e, principalmente, à metropolização. Considerando-se que há uma pluralidade de conceitos ligados a esses processos, optou-se por empregar esse tipo de análise nos artigos que apresentavam um ou mais dos seguintes conceitos, considerados no âmbito deste artigo, os mais expressivos na discussão da temática metropolitana contemporânea: metrópole, região metropolitana, área metropolitana, aglomeração urbana, aglomeração metropolitana, metropolização, cidade global, cidade mundial, megalópole, cidade-região, cidade-região global, macrometrópole. Ressalta-se que não foram considerados conceitos compostos, como, por exemplo, Região Metropolitana de Curitiba ou Macrometrópole de São
Paulo, por considerar que tratam de análises mais específicas.

Após essa primeira etapa, de cunho mais quantitativo, a análise pautou-se na tentativa de identificação da matriz teórico-conceitual ou da árvore conceitual existente nos textos publicados nos Cadernos Metrópole. Ou seja, a abordagem pretendeu detectar quais são as concepções analíticas (conceitos, teorias, autores, obras) que nortearam a construção das pesquisas e embasaram as discussões sobre a temática metropolitana presente na revista. Entende-se que a compreensão dos fenômenos perpassa, ao menos inicialmente, sua situação em relação ao que já é conhecido, pelas formulações efetuadas por aqueles que se debruçaram anteriormente sobre eles (Firkowski, 2013). Assim, os conceitos são fundamentais para que o fenômeno analisado, mesmo que se trate de um fragmento de realidade, seja contextualizado e possa ser compreendido no âmbito de uma teoria mais ampla. Contrariamente, 0 uso pouco atento de determinados conceitos (como, por exemplo, utilizados indiscriminadamente para explicar fenômenos de realidades distintas para os quais foram originalmente construídos), pode dificultar o entendimento da realidade analisada.

Por isso, nesta etapa, observaram-se a definição dada para cada um dos conceitos indicados e as obras e os autores utilizados para tal. Contudo, a análise não se restringiu à perspectiva bibliométrica, cujo resultado seria apenas a indicação dos quantitativos relacionados ao uso dos conceitos priorizados, foi além, na medida em que se dedicou, também, ao trabalho de leitura dos artigos publicados, independentemente de os conceitos estarem ou não indicados nas 
palavras-chave. Para os artigos em que havia explicitação dos conceitos, observou-se qual a definição indicada, bem como quais autores e obras utilizados para isso. A partir do material organizado, pôde-se identificar a matriz teórico-conceitual que orientou os textos publicados na revista ao longo de sua existência. Ressalta-se que os resultados obtidos não são exclusivos desta revista, afinal, a consolidação dos Cadernos Metrópole tem favorecido a publicação de artigos de autores de distintas instituições e de diferentes áreas do conhecimento (geografia, arquitetura e urbanismo, sociologia, demografia, etc.), o que permite, mesmo que minimamente, extrapolar os resultados para a produção científica, principalmente brasileira, referente aos temas urbanização e metropolização.

\section{Os conceitos selecionados e seus conteúdos}

Embora os Cadernos Metrópole sejam editados desde o ano de 1999, a inserção de palavras-chave foi iniciada apenas no ano de 2002, a partir do n. 7. Assim, a análise da recorrência dos conceitos selecionados considerou o período entre 2002 e $2017,{ }^{4}$ no qual foram publicados 378 artigos. Dentre estes, apenas 63 continham algum dos conceitos priorizados neste trabalho. No Quadro 1 é possível observar a presença de cada um dos conceitos considerados ao longo dos anos analisados.

Como pode ser observado, as palavras-chave mais utilizadas, no contexto dos conceitos selecionados, são: metrópole, região metropolitana e metropolização. ${ }^{5}$ Entende-se que, além de tais palavras-chave estarem relacionadas diretamente à temática abordada pela revista, refletem questões importantes sobre a realidade contemporânea, em especial, a urbana/metropolitana: a escala cada vez mais ampla do processo de metropolização, ampliando a quantidade de espaços metropolizados; as metrópoles como espacialidades relevantes e essenciais à acumulação do capital; a problemática da institucionalização e da gestão das regiões metropolitanas no Brasil, dentre outros aspectos.

Entre os demais conceitos, a indicação de palavras-chave é visivelmente menor, e alguns deles não são sequer mencionados (aglomeração metropolitana, cidade-mundial, megalópole, cidade-região global e macrometrópole). Tal situação evidencia que, apesar de a discussão metropolitana estar presente em todos os artigos do periódico, a pluralidade de abordagens possíveis resulta em temáticas particulares e que acabam não se relacionando com alguns conceitos norteadores, apesar da sua interface. Com isso, a metrópole, tomada como recorte espacial, está presente de modo subliminar, a priori, mas com o objetivo de priorizar a discussão sobre outros temas que incidem sobre esse recorte. Como exemplo, podem ser citadas algumas palavras- chave que demonstram esse caso: mudanças climáticas, bacias hidrográficas, enclave étnico, refugiado, efeitos na saúde humana, turismo cultural, etc. Em todos esses casos, a discussão dá-se no âmbito da metrópole, muito embora seu significado possa ser diverso, na medida em que a discussão conceitual não se coloca como prioritária. 
Quadro 1 - Cadernos Metrópole:

conceitos selecionados indicados como palavras-chave (2002-2017)

\begin{tabular}{|l|c|}
\hline \multicolumn{1}{|c|}{ Conceitos } & Total de indicações \\
\hline Metrópole(s) & 28 \\
Região(ões) metropolitana(s) & 16 \\
Área(s) metropolitana(s) & 2 \\
Aglomeração urbana & 1 \\
Aglomeração metropolitana & 0 \\
Metropolização & 12 \\
Cidade(s) global(ais) & 2 \\
Cidade mundial & 0 \\
Megalópole & 0 \\
Cidade(s)-região & 3 \\
Cidade-região global & 0 \\
Macrometrópole & 0 \\
\hline
\end{tabular}

Fonte: Cadernos Metrópole (2002-2017).

Especificamente sobre a recorrência temporal, o que, segundo Silva (2004), proporciona um panorama da evolução cronológica da produção científica, o levantamento não permitiu observar períodos específicos em que determinados conceitos passaram a ser utilizados. Essa circunstância pode ser explicada pelo recorte temporal não ser tão extenso e pelo fato de que os conceitos selecionados foram construídos anteriormente ao período analisado.

0 levantamento quantitativo é útil para traçar um quadro geral da recorrência dos conceitos, contudo, não é suficiente para que se conclua acerca do alinhamento a uma matriz teórico-conceitual.
Para tanto, o levantamento da matriz teórico-conceitual presente nos Cadernos $\mathrm{Me}$ trópole foi realizado com base na análise de todos os artigos publicados nessa revista. Do conjunto dos conceitos selecionados para a análise, foram verificados quais eram discutidos nos artigos, bem como qual o referencial teórico utilizado para fazê-lo. Os resultados podem ser observados no Quadro 2.

Constata-se que os conceitos mais discutidos nos Cadernos Metrópole são os de metrópole, cidade-global e região metropolitana. Concernente ao conceito de metrópole, a sua recorrência pode ser explicada tanto pelo objetivo inicial do periódico, 
Quadro 2 - Cadernos Metrópole: conceitos selecionados presentes nos textos

\begin{tabular}{|c|c|c|c|c|c|c|c|c|c|c|c|c|c|c|c|c|c|c|c|}
\hline Conceitos & ஜ & ঃ & ¿্ণ & ণั & 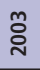 & ষ্ণ & ஜ̊ํํ & ஜ্ & ¿্ণ & $\stackrel{\text { ¿ }}{\circ}$ & ஜ्रे & $\frac{0}{\circ}$ & $\bar{i}$ & $\frac{m}{i}$ & $\frac{\nabla}{i}$ & $\frac{\operatorname{Ln}}{\delta}$ & $\frac{0}{i}$ & $\bar{\sim}$ & సٓ \\
\hline Metrópole(s) & & & & 1 & & 1 & 1 & & & 1 & 1 & 3 & & & & 1 & & 7 & 16 \\
\hline Região(ões) metropolitana(s) & & & & & & & 2 & & 1 & & 1 & & 1 & & 1 & 1 & & 5 & 12 \\
\hline Área(s) metropolitana(s) & & & & & & & 1 & & & 1 & 1 & 1 & 1 & & & 1 & & 2 & 8 \\
\hline Aglomeração urbana & & & & 1 & & & 2 & & & & & & & & & & & 2 & 5 \\
\hline Aglomeração metropolitana & & & & & & & 1 & & & & & & & & & & & & 1 \\
\hline Metropolização & & & 1 & 1 & & & 1 & & 1 & 1 & 1 & & & & & & & 2 & 8 \\
\hline Cidade(s) global(ais) & 2 & 3 & 2 & & & 1 & 1 & 1 & & 1 & & 1 & 3 & & & & & & 15 \\
\hline Cidade mundial & 2 & & & & & & 2 & & & & & & & & & & & & 4 \\
\hline Megalópole & & & 1 & & 1 & & & & & & & & & & & & & & 2 \\
\hline Cidade(s)-região & & & & & & & & & 1 & 1 & & 1 & & & 1 & & 1 & 1 & 6 \\
\hline Cidade-região global & & & & & 1 & & & & & & & & & & & & & & 1 \\
\hline Macrometrópole & & & & & & & & & & & & & & 2 & & & & 2 & 4 \\
\hline
\end{tabular}

Fonte: Cadernos Metrópole (1999-2017).

Notas: (-) Sem definição de conceito / não foram indicados os anos sem ocorrência.

qual seja, o de difundir os resultados das análises comparativas entre as metrópoles brasileiras, quanto pela ampliação da abrangência da revista, na medida em que mais pesquisadores passaram a contribuir com os Cadernos Metrópole. Outro aspecto a ser considerado está relacionado ao fato de que as metrópoles concentram pessoas, informações, mercados, empresas, etc. (Leroy, 2000), e isso faz com que elas adquiram uma complexidade tal, que mobiliza crescentemente estudiosos para compreendê-las, ampliando, assim, a produção acadêmica, que tende a se concentrar em periódicos especializados sobre o tema.
Porém, é necessário realizar algumas ressalvas a respeito, tendo em vista que quase a metade da discussão conceitual sobre metrópole ocorreu somente em um número da revista (número 40, 2017, dossiê "Metropolização e diferenciações regionais"). Assim, o que se observa é que, apesar de a metrópole aglutinar a maior parte dos artigos presentes na revista, 0 conceito é pouco discutido. Isso pode ser constatado, inclusive, pela diferença significativa entre as indicações nas palavras-chave (28 vezes) ${ }^{6}$ e a quantidade de vezes em que houve a preocupação em conceituar a metrópole, objeto de análise no texto (16 vezes). A metrópole 
aparece, como apontado anteriormente, como um pano de fundo para determinados fenômenos ou problemáticas, embora estes estejam estritamente relacionados a essa espacialidade e não possam ser dissociados dela ou ainda como um termo que não necessitaria de maiores explicações, uma vez que sua " [...] noção é de uso corriqueiro no cotidiano [...]", apesar de carregar em seu interior uma grande complexidade (Firkowski, 2013, p. 23).

A respeito da região metropolitana, também é possível constatar que quase a metade da discussão ocorreu somente em um número da revista (número 40, 2017, dossiê "Metropolização e diferenciações regionais"). Apesar da existência de inúmeros artigos que se dedicaram a discutir as regiões metropolitanas brasileiras, em poucos foram observadas definições ou as especificidades de sua institucionalização. Voltaremos a isso oportunamente.

Especificamente sobre cidade global, tal situação se diferencia da verificada na análise bibliométrica, afinal, esse conceito foi citado poucas vezes nas palavras-chave (2 vezes) e, contrariamente, na análise conceitual, configurou-se como um dos que mais suscitou algum tipo de debate, em vários números do referido periódico. ${ }^{7}$

Considera-se que tal situação decorre, inicialmente, das hipóteses norteadoras da pesquisa que estava sendo desenvolvida no âmbito do Grupo de Pesquisa Pronex: "Metrópole, desigualdades socioespaciais e governança urbana: Rio de Janeiro, São Paulo e Belo Horizonte" e que originou o periódico. 0 Grupo de pesquisa era unificado teórica e metodologicamente pelo diálogo com o debate relativo às cidades globais e buscava testar a hipótese de que haveria vínculos estruturais " [...] entre a globalização das economias urbanas e a intensificação de sua dualização social" (Ribeiro e Bógus, 1999, p. 4). Nesse sentido, embora os três primeiros números tenham sido dedicados exclusivamente aos resultados da pesquisa, a continuidade das análises propiciou 0 desenvolvimento de novos artigos. Além disso, pode-se acrescentar o fato de que os Cadernos Metrópole passaram a receber crescentemente contribuições externas ao grupo de pesquisas original, dentre aquelas que se debruçavam sob a perspectiva teórica das cidades globais, permitindo a manutenção da discussão em torno desse conceito ao longo do tempo. Contrariamente ao conceito de metrópole, entende-se que o de cidade global é mais complexo, por isso, o esforço maior em precisá-lo.

Os demais conceitos aparecem com menos frequência nas discussões, e algumas considerações a seu respeito serão efetuadas posteriormente.

A análise do referencial utilizado na discussão dos conceitos permitiu identificar, em alguns casos, a matriz teórico-conceitual que orienta os trabalhos. Salienta-se que, enquanto na discussão de parte dos conceitos há uma convergência em torno de determinados autores e obras, em outros isso não ocorre, havendo um rol mais amplo e diverso de estudiosos de referência. Dessa forma, dentre os conceitos considerados nesta análise, os que apresentaram maior convergência em relação a algumas obras e autores foram os de cidade global, cidade-região e cidade mundial (Quadro 3). ${ }^{8}$

Destaca-se que o conceito de cidade global, proposto por Saskia Sassen no início da década de 1990, teve como base as discussões desenvolvidas por Peter Hall (1966), 


\section{Quadro 3 - Conceitos com maior convergência nos autores de referência utilizados}

\begin{tabular}{|c|c|c|}
\hline Conceito & Autor(a/es) mais citado(a/s) & Obra(s) utilizada(s)* \\
\hline Cidade global & Saskia Sassen & $\begin{array}{l}\text { - The Global City. New York, London, Tokyo. } \\
\text { - Cities in the World Economy. } \\
\text { - Globalization and its discontents: essays on the new } \\
\text { mobility of people and money. } \\
\text { - On concentration and centrality in the global city. } \\
\text { - Territory, authority, rights: from medieval to global } \\
\text { assemblages. } \\
\text { - Una sociología de la globalización. } \\
\text { - The global cities. Paper prepared for presentation at the } \\
\text { conference on cities and space to be held in Belo Horizonte. }\end{array}$ \\
\hline Cidade-região & $\begin{array}{l}\text { Allen J. Scott, John Agnew, } \\
\text { Edward Soja e Michael Storper }\end{array}$ & $\begin{array}{l}\text { - From the political economy of regions to regional political } \\
\text { economy. }{ }^{1} \\
\text { - Globalization and the rise of city-regions. }{ }^{2} \\
\text { - La economía metropolitana: organización industrial y } \\
\text { crecimiento urbano. }^{2} \\
\text { - Cidades-regiões globais. }{ }^{3}\end{array}$ \\
\hline Cidade mundial & Saskia Sassen & $\begin{array}{l}\text { - The global city: New York, London, Tokyo. } \\
\text { - Ciudades en la economía global: enfoques teóricos y } \\
\text { metodológicos. } \\
\text { - El Estado y la nueva geografía del poder. }\end{array}$ \\
\hline
\end{tabular}

Fonte: Cadernos Metrópole (1999-2017).

Notas: $\left(^{*}\right)$ há obras que foram utilizadas como referência em vários artigos, portanto, mais de uma vez.

(1) Autoria de John Agnew.

(2) Autoria de Allen J. Scott.

(3) Autoria de Allen J. Scott, John Agnew, Edward Soja e Michael Storper.

John Friedmann e Goetz Wolff (1982) e John Friedmann (1986) a respeito das cidades mundiais, além de incorporar as reflexões sobre a cidade informacional de Manuel Castells (1989) (cf. Moura, 2009). Por isso, quando se analisa o referencial teórico utilizado nas discussões a respeito de cidade global, além de Sassen, que é a autora majoritária, estão presentes também os demais citados anteriormente, porém em menor número de trabalhos, como é o caso de Manuel Castells, Jordi Borja e John Friedmann. ${ }^{9}$ Isso, de certa forma, evidencia a preocupação de alguns autores com a construção dos conceitos ao longo do tempo. Além disso, constata-se que em certos casos não houve distinção entre cidade global e cidade mundial, por isso, o referencial teórico do primeiro é utilizado para explicar o segundo conceito, fato que justifica as obras de Saskia Sassen aparecerem como as principais referências de cidade mundial. Merece destaque o fato de que os primeiros autores que refletiram sobre as cidades mundiais não aparecem como referência dos artigos que buscam discutir esse conceito.

Como pode ser observado no Quadro 3, a discussão sobre cidade-região está atrelada principalmente às publicações de Allen J. Scott, John Agnew, Edward Soja e Michael 
Storper, seja por meio de obras produzidas isoladamente pelos autores, seja em publicações em conjunto, como é o caso do texto Cidades-regiões globais. ${ }^{10} 0$ referencial desenvolvido no início dos anos 2000 pelos autores tem sido utilizado em artigos dos Cadernos Metrópole para explicar alguns dos maiores espaços metropolitanos da América Latina; está presente em todos os textos em que se discute, mesmo que minimamente, o conceito de cidade-região. No entanto, convém evidenciar uma característica relevante relacionada a esse conceito: enquanto a produção sobre cidade global presente nos Cadernos Metrópole está estreitamente relacionada ao desenvolvido por Sassen, o de cidade-região, nos últimos anos, tem incorporado também a contribuição de autores latino-americanos que buscam apresentar elementos explicativos sobre a realidade na qual estão inseridos. Dessa forma, passam a compor o quadro de referências de cidade-região os trabalhos de Pradilla Cobos (2009), Sandra Lencioni (2003 e 2006b), Rosa Moura (2009) e Felipe N. C. Magalhães (2008). Isso suscita duas ordens de reflexões, uma que está diretamente relacionada à natureza diferenciada de ambos os conceitos, na medida em que o conceito de cidade global se presta a uma análise mais relacionada ao papel de comando de algumas poucas cidades numa rede urbana mundial, enquanto o conceito de cidade-região se mostra mais operacional, ao evidenciar elementos da estrutura e da morfologia em âmbito intrametropolitano, o que resulta na segunda reflexão, ou seja, o fato de o conceito de cidade-região possuir, desse modo, um caráter mais aplicado à realidade latino-americana, permitindo que seja utilizado num rol maior de casos em análise.
Enquanto nos artigos que trazem os conceitos de cidade global, cidade mundial, cidade-região e cidade-região global é possível identificar facilmente uma matriz teórico-conceitual, nos outros essa tarefa não é tão simples, pois as referências são diversas e plurais. Excetuando-se os conceitos de macrometrópole e megalópole, não tão usuais, os demais se alinham com 0 afirmado anteriormente a respeito de seu uso corriqueiro. Por isso, entende-se que há um rol bastante grande de obras utilizadas, sem polarização de um determinado autor, embora alguns sejam mais citados do que outros. Do mesmo modo, foi possível identificar definições sem referência direta a alguma bibliografia.

Considerando inicialmente os conceitos com maior quantidade de discussões (excetuando-se os já abordados), quais sejam, metrópole, região metropolitana, área metropolitana e metropolização, tentar-se-á mostrar qual o referencial teórico que alimenta os debates a respeito. Nesse sentido, tendo em vista as discussões sobre região metropolitana, constata-se que, diferentemente das demais, estas se baseiam principalmente em autores nacionais, afinal, trata-se de uma proposição institucionalizada por lei, não fundamentada necessariamente em processos socioespaciais de metropolização. ${ }^{11}$ Por isso, o referencial utilizado para conceituar as regiões metropolitanas abrange desde leis, como constituições estaduais e o recente Estatuto da Metrópole, até estudiosos que discutem a temática há algum tempo no Brasil ,como Luiz César de Q. Ribeiro, Maria L. G. Castello Branco, Olga L. C. de Freitas Firkowski, ${ }^{12}$ dentre outros.

Já os conceitos de metrópole, área metropolitana e metropolização, por refletirem 
espacialidades e processos, presentes em inúmeras e diversas realidades, são discutidos não apenas com base em autores nacionais, mas também e principalmente internacionais. 0 referencial, embora contenha reflexões efetuadas por autores brasileiros, assenta-se sobretudo em obras desenvolvidas a partir de outras realidades, principalmente a europeia. Assim, dos cinco autores utilizados para definir área metropolitana, quatro são estrangeiros; e, dos seis autores que servem de referência para a conceituação de metropolização, cinco são de outros países. ${ }^{13}$ Obviamente que isso decorre do fato de que muito do referencial utilizado nas pesquisas que discutem o urbano/metropolitano foi desenvolvido a partir de realidades na qual o processo de metropolização e os espaços metropolitanos e metropolizados atingem escalas muito mais amplas, tal qual a dos países desenvolvidos. 0 conceito de metrópole diferencia-se um pouco, na medida em que há mais autores nacionais como referência. No Quadro 4 está uma tentativa de demonstrar a pluralidade de autores utilizados na definição dos três conceitos.

Em relação aos conceitos de aglomeração urbana, aglomeração metropolitana, megalópole e macrometrópole, constatou-se menor expressividade quanto à conceituação;

\section{Quadro 4 - Autores utilizados na definição de metrópole, área metropolitana e metropolização}

\begin{tabular}{|c|c|}
\hline Conceito & Autor(a/es) e quantidade de artigos em que foram indicados* \\
\hline Metrópole & $\begin{array}{l}\text { François Ascher (3); Henri Lefebvre (2); Olga L. C. de Freitas Firkowski (2); Milton } \\
\text { Santos; Bernadette Merenne-Schoumaker; Luís C. de Q. Ribeiro; Clementina de } \\
\text { Ambrosis; A.M.L. Moreira; F. Dureau, V. Dupont, E. Leliévre, J.-P. Lévy e T. Lulle; } \\
\text { Dureau, V. e J.-P. Lévy; Sandra Lencioni; Edward Soja; Ralfo Matos; Pierre Veltz; } \\
\text { Flávio Vilaça; Jordi Borja e Manuel Castells; Brasil'; Silvia de Castro Bacellar do } \\
\text { Carmo; Maria do Livramento Miranda Clementino e Lindijane de Souza Bento; } \\
\text { Marco Aurélio Costa e Isadora Tami L. Tsukumo; Ruskin Freitas. }\end{array}$ \\
\hline Área metropolitana & $\begin{array}{l}\text { Patrick Geddes; W.H. Frey e A. Speare Jr.; Jordi Borja e Manuel Castells; Olga L. C. } \\
\text { de Freitas Firkowski; Francesco Indovina. }\end{array}$ \\
\hline Metropolização & $\begin{array}{l}\text { François Ascher; C. Lacour e S. Puissant; F. Dureau, V. Dupont, E. Leliévre, J.-P. } \\
\text { Lévy e T. Lulle; F. Dureau e J.-P. Lévy; Sandra Lencioni; Edward Soja. }\end{array}$ \\
\hline
\end{tabular}

Fonte: Cadernos Metrópole (1999-2017).

Nota: $\left({ }^{*}\right)$ os autores sem indicação de quantidade foram citados uma vez e estão organizados por ordem de aparição. As respectivas obras estão indicadas nas referências, ao final deste texto.

(1) não se trata de um autor, mas de lei (Estatuto da Metrópole) utilizada para definir metrópole. 
do mesmo modo, o rol de obras de referência é pequeno, porém, determinados autores e obras embasam mais de um conceito. Nesse sentido, destacam-se François Ascher (1998 e 2001), base das definições de megalópole e macrometrópole; Rosa Moura (2008 e 2009) e Rosa Moura, Libardi e Barion (2006), referência para a conceituação de aglomerações urbanas e macrometrópole; e Luís César de Q. Ribeiro (2004a e 2012), organizador de publicações que serviram de base para as definiç̧ões de aglomeração metropolitana e macrometrópole. Para os conceitos de aglomeração urbana e macrometrópole também se constatou o uso de leis (Estatuto da Metrópole) e de documentos produzidos por instituições públicas, como o Instituto Brasileiro de Geografia e Estatística (IBGE) e a Empresa Paulista de Planejamento Metropolitano S.A. (Emplasa).

Observa-se, no caso da macrometrópole, a tentativa de aproximação de uma denominação atribuída pela Emplasa ao conjunto constituído pelas Regiões Metropolitanas de São Paulo, Baixada Santista, Campinas, Sorocaba do Vale do Paraíba e Litoral Norte, além das Aglomerações Urbanas de Jundiaí e Piracicaba (Emplasa, 2018), à discussão teórico-conceitual proposta por autores como Ascher (2001), como pode ser observado no trecho a seguir:

A Macrometrópole Paulista apresenta-se como um território denso, mas descontínuo, de áreas urbanizadas, e articulado, de forma heterogênea, pela intensificação do fluxo de pessoas, mercadorias e informações, formando muitas vezes espaços fragmentados e policêntricos (Ascher, 2001), de acordo com os atrativos de determinada região. (Fanelli; Santos Júnior, 2013, p. 464)
Cabe notar que a natureza da macrometrópole se aproxima mais da perspectiva institucional, ao representar um espaço de abrangência de regiões metropolitanas e aglomerações urbanas, diferente, portanto, da discussão empreendida por Ascher, ao priorizar o processo espacial, tendo em vista que parte da realidade francesa; a despeito disso, a formulação desse autor foi tomada como referência para explicar o caso brasileiro.

Se, por um lado, a análise do referencial teórico permitiu a identificação dos autores e obras mais representativos na definição dos conceitos selecionados, o que de uma certa forma favoreceu o avanço da identificação de uma matriz teórico-conceitual presente nos Cadernos Metrópole, de outro, possibilitou constatar que, em alguns artigos, diferentes conceitos foram utilizados como sinônimos. Apesar dos conceitos considerados na presente análise terem como base as transformações pelas quais os espaços urbano/metropolitanos vêm passando nas últimas décadas, a construção de alguns parte de realidades específicas e concepções diversas sobre o processo de metropolização. Alguns autores consideram mais relevante a tecnologia, outros a concentração do terciário moderno, outros ainda a materialização desses espaços metropolitanos. Considerar como equivalentes conceitos que têm na origem uma concepção distinta pode se configurar como um problema para o avanço da compreensão dos espaços metropolitanos.

É o que se observa a seguir, quando foram tomados, como similares, conceitos distintos.

No contexto da globalização da economia e do impacto das tecnologias, em especial das telecomunicações e da informática, 
a cidade de São Paulo tem sido considerada como uma das cidades mundiais e vem apresentando processos comuns a essas megalópoles [...]. Como nas demais cidades globais, muitos estudos têm enfatizado a dualização social em São Paulo. (Véras, 1999, p. 74; grifos nossos)

São Paulo hoje está sendo considerada uma das cidades mundiais do planeta [...]. Ao debater algumas das diferentes faces e enigmas dessa cidade mundial, em especial no que se refere à sua dinâmica intraurbana, a seus territórios, à segregação social, empreende-se também breve discussão sobre os impactos da globalização sobre as cidades e a adequação do conceito de cidade global e seus indicadores. (Bógus e Veras, 2000, p, 90; grifos nossos)

Esses polos urbanos direcionais, as chamadas cidades mundiais ou cidades-regiões globais, com suas complexas redes de empresas [...]. (Gaspar, 2005, p. 33; grifos nossos)

Como pode ser observado pelos fragmentos apresentados, o conceito de cidade mundial é concebido como equivalente a outros com significações distintas, nas proposições originais de seus autores. Assim, por mais que o conceito de cidade global tenha sua gênese naquele de cidade mundial, contém alguns elementos explicativos que o tornam diferente, portanto, um novo conceito. Isso também é válido para cidade-região global, que compartilha algumas hipóteses da cidade-global, mas se distingue de outras.

Além do uso de tais conceitos como equivalentes, a análise também revelou que, em alguns casos, para análises específicas sobre a realidade brasileira, não houve a distinção entre metrópole e região metropolitana, ou seja, entre a dinâmica espacial e o fato institucional. Ou ainda, o conceito de região metropolitana foi usado para definir as áreas e aglomerações metropolitanas.

[...] as grandes metrópoles brasileiras continuam se caracterizando não só por concentrarem a maior parte da riqueza nacional, como também por possuírem expressivos focos de pobreza e de exclusão social: encontram-se nas regiões metropolitanas $8 \%$ dos pobres e $90 \%$ dos domicílios localizados em favelas [...]. (Azevedo; Santos Júnior e Ribeiro, 2009, p. 350; grifos nossos)

Partindo do exposto, até o momento, parece clara a configuração de dois modelos do espaço capitalista. Um é decorrente do modo de produção industrial que levou à explosão urbana e à configuração do crescimento das metrópoles e de suas regiões metropolitanas. 0 outro, expressão espacial do capitalismo pós-industrial ou contemporâneo, é a extensão das regiões metropolitanas, que assumem novos contornos, devido às transformações econômicas e à nova configuração da indústria moderna, dando início às dinâmicas de dispersão urbana. (Eigenheer e Somekh, 2017, p. 780; grifos nossos)

[...] regiões metropolitanas [...] essas serem aglomerados com grande concentração econômica, social, política e cultura que, ao mesmo tempo, resultam em profundas desigualdades internas [...]. (Silveira e Muniz, 2014, pp. 260-270; grifos nossos)

Também merecem destaque casos, como o a seguir, que explicita o que está assumindo em relação a determinado conceito: 
Considera-se região metropolitana 0 agrupamento de municípios limítrofes que assuma destacada expressão nacional, em razão da elevada densidade demográfica, significativa conurbação e de funções urbanas e regionais com algo grau de diversidade, especialização e integração socioeconômica [...]. (Carmo e Falcoski, 2005, pp. 131-132, com base na Constituição Estadual de São Paulo)

Destaca-se que, no Brasil, nem todas as regiões metropolitanas são de fato metropolitanas ou têm todos os seus municípios integrantes com características que permitem defini-los como metropolitanos. Assim, de acordo com Firkowski (2013), foram identificados casos em que o principal centro urbano de algumas das regiões metropolitanas no Brasil era classificado, segundo o Regic, como centro local, portanto, com centralidade e influência que não ultrapassavam seus limites municipais. Isso porque, desde 1988, as regiões metropolitanas são definidas pelos estados e, até 2015, quando foi aprovado o Estatuto da Metrópole, não havia critérios objetivos para sua criação. Dessa forma, torna-se inadequado tomar a região metropolitana como equivalente à metrópole, ou seja, igualar o processo espacial com o fato institucional, mesmo no caso das áreas com urbanização mais consolidada.

Além disso, outro elemento a se considerar se refere ao uso, sem ressalvas, de conceitos que foram construídos para explicar realidades muito particulares. A seguir, nota-se que os autores discutem sobre as metrópoles brasileiras e, para isso, também utilizam as noções de megalópoles e metápolis e da própria metrópole, como sinônimos, evidenciado pelo uso do "ou" na formulação.
Nossas metrópoles, megalópoles ou metápoles não têm apresentado respostas às demandas por espaços que convidem ao encontro, devido à transformação dos espaços públicos em espaços de passagem. (Dias e Esteves Júnior, 2017, p. 638; grifos nossos)

Salienta-se que megalópole foi um conceito proposto por Jean Gottmann no início da década de 1960 para descrever o nordeste dos Estados Unidos que, naquele momento, apresentava uma grande extensão urbana conurbada, resultado do crescimento de várias cidades e do encontro de suas áreas urbanas. Tal situação seria propiciada pela concentração de população e atividades e existência de novos meios de transporte e comunicação. Além disso, para Gottmann, as megalópoles seriam um fenômeno característico de países desenvolvidos (cf. Moura, 2009). Já o conceito de metápolis (uma contração de metametrópole) foi desenvolvido por François Ascher, a partir da realidade francesa, e manifesta uma configuração espacial formada por espaços heterogêneos e não necessariamente contíguos, nos quais seus habitantes e atividades econômicas estão integrados ao funcionamento cotidiano de uma metrópole. Contribui, para isso, a emergência de um sistema urbano que funciona em rede, por isso, a importância do desenvolvimento e da existência das infraestruturas viárias e dos transportes rápidos (TGV - Trem de Grande Velocidade, por exemplo) (Ascher, 1995).

Além disso, diante da grande quantidade de conceitos construídos ao longo das últimas décadas, alguns autores têm manifestado preocupação em relação ao seu uso indiscriminado. Tal foi objeto de reflexão em alguns 
artigos publicados nos Cadernos Metrópole, como o de Gaspar (2011), que argumenta que há, em alguns casos, abusos nos usos das terminologias de cidade-região, megalópole, megacidade, dentre outras. Arrais (2008) adverte sobre o uso de determinados conceitos em realidades e territórios diferentes para os quais foram originalmente pensados, e Núñez e Roze (2014) argumentam que a generalização e a reprodução acrítica de conceitos (cidade global, cidade informacional, cidade dual, etc.) ignoram as particularidades socioterritoriais e tornam homogêneos os processos sociais.

Em relação às diferenças entre metrópole/metropolização e regiões metropolitanas no Brasil, do mesmo modo, alguns artigos publicados nos Cadernos Metrópole, em especial, os mais recentes, buscam discutir e evidenciar essa distinção. Tal é o caso dos textos de Clementino e Almeida (2015), Gomes et al. (2017), Santos (2017), Silva, Cunha e Ortega (2017) e Souza e Terra (2017), em que os autores diferenciam metrópole e o processo de metropolização da institucionalização de regiões metropolitanas no Brasil. ${ }^{14}$

\section{Considerações finais}

Finalizada esta análise, algumas observações merecem destaque, a primeira, mais simples e operacional, diz respeito à relação entre conteúdo e palavras-chave, há, em muitos casos, ausência de uma relação direta entre a indicação de palavras-chave e o que foi efetivamente objeto de análise nos textos trabalhados. Isso pode ser importante, tendo em vista a crescente disponibilização de bases de dados nas quais as palavras-chave, ao lado de resumos bem elaborados e precisos, representam um convite à leitura e ao aprofundamento dos textos, bem como se constituem em bases de pesquisa e consulta, como a ora realizada.

Para além dessa observação, e priorizando o olhar sobre todo o processo, podemos concluir que a análise bibliométrica permite uma aproximação geral acerca dos temas discutidos, porém, apenas sob a perspectiva quantitativa, o que não é suficiente, quando se deseja reconhecer a matriz teórico-conceitual que envolve determinado tema. Neste texto, não foi possível verificar a evolução cronológica da produção científica referente aos conceitos considerados.

Após o reconhecimento dos conceitos pela sua incidência , procedeu-se à análise conceitual, que permitiu identificar quais obras e autores que embasaram as discussões de determinados conceitos, em especial, para os de cidade global, cidade-região e cidade mundial. Para os demais conceitos, a discussão é mais pulverizada, embora, mesmo assim, possam se identificar alguns autores mais recorrentes.

Deve-se registrar, também, a ampliação de autores brasileiros nas discussões, principalmente nos últimos anos e, em especial, para o conceito de cidade-região e metrópole. Isso demonstra a importância das pesquisas desenvolvidas no Brasil sobre a temática.

A supremacia de certos conceitos em relação a outros também merece um comentário. Pode-se concluir que a recorrência de incorporação do conceito de "cidade-região" parece estar vinculada ao fato de o texto basilar dessa discussão ter sido publicado no Brasil em 2001 pela Revista Espaço e Debates, fato, 
por exemplo, que não se repetiu em relação ao conceito de metápolis, cuja publicação, no Brasil, nunca ocorreu, limitando o acesso e a ampliação da discussão sobre ele.

A análise apontou também para o fato de que, em alguns textos, diferentes conceitos foram tratados como sinônimos, assim como também não se colocou como vigorosa a distinção entre metrópole e região metropolitana, no caso brasileiro, igualmente, certos conceitos construídos para explicar realidades distintas da nossa foram aplicados sem ressalvas quanto ao seu poder de explicação.

Finalmente, observou-se, na maioria dos artigos, a inserção da metrópole como o continente de processos diversos, como recorte espacial, mais do que como realidade complexa em si. Nesses textos, nos quais a preocupação não foi propriamente com a questão conceitual que envolve esse objeto, é que se observou a maioria dos casos de utilização de conceitos diversos como sinônimos.

O olhar sobre a natureza do que está sendo produzido no âmbito da revista $\mathrm{Ca}$ dernos Metrópole, acerca da metrópole e da metropolização, pareceu-nos importante, por situar como temos nos posicionado diante dessa temática, em especial numa revista que carrega, como afirmado no início deste texto, a metrópole em seu próprio nome.

\section{[I] https://orcid.org/0000-0001-5840-2377}

Universidade Federal do Paraná, Setor de Ciências da Terra, Departamento de Geografia. Observatório das Metrópoles, Núcleo Curitiba. Curitiba, PR/Brasil.

olgafirk@gmail.com

\section{[II] https://orcid.org/0000-0002-7182-191X}

Instituto Federal do Paraná. União da Vitória, PR/Brasil. pbaliski@gmail.com

\section{Notas}

(1) Conforme "Apresentação" do Cadernos Metrópole n. 1 (1999, p. 3).

(2) Quantidade de números publicados até dezembro de 2017. Informações retiradas da página dos Cadernos Metrópole (http://cadernosmetropole.net/), em janeiro de 2018.

(3) O sentido aqui atribuído à árvore conceitual se refere à tentativa de identificar a matriz, o tronco conceitual dos conceitos tratados nos textos, acolhendo desdobramentos, reinterpretações, etc.

(4) Até o número 40. 
(5) Tendo em vista todas as palavras-chave indicadas e excetuando-se aquelas que se referem aos conceitos considerados, as que também se destacam em quantidade de citações são: urbanização, gentrificação e planejamento urbano, com respectivamente, 20, 20 e 15 ocorrências.

(6) Diferentemente, nas palavras-chave, o conceito de metrópole aparece distribuído ao longo dos anos.

(7) Essa situação demonstra como nem sempre a pesquisa por palavras-chave pode levar aos artigos que discutem um determinado tema.

(8) O conceito de cidade-região global também foi ao encontro do referencial teórico indicado no Quadro 1, no entanto, como foi discutido apenas em um artigo, não há como afirmar que há uma convergência.

(9) Castells (1989), Borja e Castells (1997), Friedman (1986), Friedman (1995).

(10) Scott, Agnew, Soja e Storper (2001).

(11) Com exceção do artigo de Pírez (2005) que trata do caso argentino e, portanto, possui outro significado.

(12) Ribeiro, Silva e Rodrigues (2011); Castello Branco et al. (2013); Firkowski (2012)..

(13) É importante destacar que as considerações realizadas estão baseadas unicamente na definição dada aos conceitos. Isso não significa que no restante da discussão realizada nos artigos não estejam presentes autores que tratem da realidade existente em países em desenvolvimento.

(14) Constatou-se que uma referência comum para a distinção da dinâmica do fato institucional em dois dos textos foi o artigo de Olga Firkowski (2012). Nesse sentido, destaca-se a importância das reflexões realizadas a partir da realidade brasileira.

\section{Referências}

ARRAIS, T. A. (2008). A cidade e a região/a cidade-região: reconhecer processos, construir políticas. Cadernos Metrópole. São Paulo, n. 20, pp. 81-91. Disponível em: http://cadernosmetropole. net/system/artigos/arquivos/000/000/135/original/cm20_135.pdf?1474650648. Acesso em: jul 2012.

ASCHER, F. (1995). Metápolis ou l'avenir des villes. Paris, Odile Jacobs.

(1998). Metápolis: acerca do futuro da cidade. Oeiras, Celta.

(2001). "Metropolização e transformação dos centros das cidades". In: ALMEIDA, M. A. R. Os centros das metrópoles: reflexos e propostas para a cidade democrática do século XXI. São Paulo, Editora Terceiro Nome/Viva o Centro/Imprensa Oficial do Estado.

AZEVEDO, S. de; SANTOS JUNIOR, O. A. dos e RIBEIRO, L. C. de Q. (2009). Metrópoles, cultura política e cidadania no Brasil. Cadernos Metrópole. São Paulo, v. 11, n. 22, pp. 347-366. Disponível em: http://cadernosmetropole.net/system/artigos/arquivos/000/000/161/original/cm22_162. pdf?1474650649. Acesso em: jul 2012. 
BENKO, G. (2002). Mundialização da economia, metropolização do mundo. Revista do Departamento de Geografia, n. 15, pp. 45-54.

BÓGUS, L. M. M. e VÉRAS, M. P. B. (2000). A reorganização metropolitana de São Paulo: espaços sociais no contexto da globalização. Cadernos Metrópole. São Paulo, n. 3, pp. 81-98. Disponível em: http://cadernosmetropole.net/system/artigos/arquivos/000/000/010/original/cm3_10. pdf?1474650637. Acesso em: jul 2012.

BORJA, J. e CASTELLS, M. (1997). Local y global. La gestión de las ciudades en la era de la información. Madri, Taurus/Pensamiento.

(2004). Local y global: la gestión de las ciudades en la era de la información. Madri, Taurus.

BRASIL. Lei n. 13.089, de12 de janeiro de 2015. Institui o Estatuto da Metrópole, altera a Lei n. 10.257, de 10 de julho de 2001, e dá outras providências.

CARMO, S. de C. B. do (2004). Câmara e Agenda 21 Regional para uma rede de cidades sustentáveis: A Região Metropolitana da Baixada Santista. Dissertação de Mestrado. São Carlos, Universidade Federal de São Carlos.

CARMO, S. de C. e FALCOSKI, L. A. N. (2005). Um olhar sobre o planejamento e gestão metropolitanos. A Região Metropolitana da Baixada Santista. Cadernos Metrópole. São Paulo, n. 14, pp. 127-147. Disponível em: http://cadernosmetropole.net/system/edicoes/arquivos/000/000/016/original/ cm14.pdf?1474650643. Acesso em: nov 2011.

CASTELLO BRANCO, M. et al. (2013). Rediscutindo a delimitação das regiões metropolitanas no Brasil: um exercício a partir dos critérios da década de setenta. Rio de Janeiro, Ipea.

CASTELLS, M. (1989). The informacional city. Information technology, economic, restructuring and urban-regional process. Oxford, Basil Blackwell.

CLEMENTINO, M. do L. M. e ALMEIDA, L. de S. B. (2015). Construção técnico-política de governança metropolitana. Cadernos Metrópole. São Paulo, v. 17, n. 33, pp. 201-224. Disponível em: http://cadernosmetropole.net/system/artigos/arquivos/000/000/316/original/cm33_317. pdf?1474650662. Acesso em: dez 2017.

COSTA, M. e TSUKUMO, I. (2013). 40 anos de regiões metropolitanas no Brasil. Brasília, Ipea.

DAVIET, S. (2005). Trente ans de géographie industrielle dans les Annales de géographie (1970-1999). Annales de Géographie. Paris, Armand Colin, année 114, n. 641, pp. 73-92.

DE AMBROSIS, C. (2001). Regiões metropolitanas, aglomerações urbanas e microregiões. Fundação Prefeito Faria Lima - Cepam. Estatuto da Cidade. CD-ROM.

DIAS, M. S. e ESTEVES JÚNIOR, M. (2017). O espaço público e o lúdico como estratégias de planejamento urbano humano em: Copenhague, Barcelona, Medellín e Curitiba. Cadernos Metrópole. São Paulo, v. 19, n. 39, pp. 635-663. Disponível em: http://cadernosmetropole.net/system/artigos/ arquivos/000/000/397/original/3912.pdf?1502208111. Acesso em: jan 2018.

DUREAU, F.; DUPONT, V.; LELIÈVRE, É.; LÉVY, J.-P. e LULLE, T. (orgs.). (2000). Métropoles en mouvement: une comparaison internationale. Paris, IRD/Anthropos.

DUREAU, F. e LÉVY, J.-P. (2007). Morphologie urbaine et environnement: un état des lieux. Laboratoire techniques, territoires et sociétés. Paris, LATTS, 20 jun. 19 p. Disponível em: <http://latts.cnrs.fr/ site/p_latts.php?ld=1642>. Acesso em: 24 abr 2008. 
EIGENHEER, D. M. e SOMEKH, N. (2017). Formas avançadas de dispersão urbana no vetor noroeste paulista: eixo São Paulo-Campinas. Cadernos Metrópole. São Paulo, v. 19, n. 40, pp. 777-797. Disponível em: http://cadernosmetropole.net/system/artigos/arquivos/000/000/402/original/4004. pdf?1513011907. Acesso em: jan 2018.

EMPLASA - Empresa Paulista de Planejamento Metropolitano S. A. (2018). Macrometrópole Paulista. Disponível em: https://www.emplasa.sp.gov.br/MMP. Acesso em: maio 2018.

FANELLI, A. F. D. M. e SANTOS JUNIOR, W. R. dos (2013). O Aglomerado Urbano de Jundiaí (SP) e os desafios para a mobilidade metropolitana paulista. Cadernos Metrópole. São Paulo, v. 15, n. 30, pp. 461-487. Disponível em: http://cadernosmetropole.net/system/artigos/ arquivos/000/000/270/original/cm30_271.pdf?1474650658. Acesso em jan 2018.

FIRKOWSKI, O. L. C. F. (2012). Porque as regiões metropolitanas no Brasil são regiões, mas não são metropolitanas. Revista Paranaense de Desenvolvimento, v. 122, pp. 19-38.

(2013). “Metrópoles e regiões metropolitanas no Brasil: conciliação ou divórcio?”. In: FURTADO, B. A.; KRAUSE, C. e FRANÇA, K. C. B. de (eds.). Território metropolitano, políticas municipais: por soluções conjuntas de problemas urbanos no âmbito metropolitano. Brasília, Ipea, pp. 21-51.

FREITAS, R. (2009). Regiões Metropolitanas: uma abordagem conceitual. Humanae, v. 1, pp. 44-53.

FRIEDMAN, J. (1986). The world city hipothesys. Development and Change, v. 17, n. 1, pp. 69-84.

(1995). "Where we stand: a decade of world city research". In: KNOX, P.; SCOTT, A. J.; AGNEW, J.; SOJA, E. W. e STORPER, M. (2001). Cidades-regiões globais. Espaço e Debates, n. 41, pp. 11-25.

FREY, W. H. e SPEARE JR., A. (1995). “Metropolitan areas as functional communities". In: DAHMAN, D. C. e FITZSIMMONS, J. D. (eds.). Metropolitan and nonmetropolitan areas: new approaches to geographical definition on. Washington, Population Division/US Bureau of the Census, pp. 139190 (Working paper, 12).

GASPAR, R. C. (2005). Espaço metropolitano, política e economia global. Cadernos Metrópole. São Paulo, n. 14, pp. 31-49. Disponível em: http://cadernosmetropole.net/system/artigos/ arquivos/000/000/072/original/cm14_72.pdf?1474650643. Acesso em: nov 2011.

(2011). A economia política da urbanização contemporânea. Cadernos Metrópole. São Paulo, v. 13, n. 25, pp. 235-256. Disponível em: http://cadernosmetropole.net/system/artigos/ arquivos/000/000/209/original/cm25_210.pdf?1474650653. Acesso em: jul 2012.

GEDDES, P. (1915). Cities in evolution: an introduction to the town planning movement and the study of civics. London, Willians \& Norgate.

GOMES, T. do V.; CARDOSO, A. C. D.; COELHO, H. S. e OLIVEIRA, K. D. (2017). Santarém (PA): um caso de espaço metropolitano sob múltiplas determinações. Cadernos Metrópole. São Paulo, v. 19, n. 40, pp. 891-918. Disponível em: http://cadernosmetropole.net/system/artigos/ arquivos/000/000/407/original/4009.pdf?1513013701. Acesso em: jan 2018.

INDOVINA, F. (2004). "La ciudad difusa”. In: Lo urbano: en 20 autores contemporáneos. Barcelona, Ángel Martin Ramos.

LACOUR, C. e PUISSANT, S. (coords.) (1999). La métropolisation-croissance, diversité, fractures. Paris, Anthropos. 
LANG, R. E. e DHAVALE, D. (2005). Beyond megalopolis: exploring America's New "Megapolitan". Geography, pp. 1-33. Disponível em: https://digitalscholarship.unlv.edu/brookings_pubs/38/. Acesso em: nov 2017.

LANG, R. e KNOX, P. K. (2009). The New Metropolis: Rethinking Megalopolis. Regional Studies, v. 43, pp. 789-802.

LEFEBVRE, H. (1969). O direito à cidade. São Paulo, Documentos.

(1976). Espacio y Política. Provenza, Barcelona, Edições Península.

LEITE FILHO, G. A. e SIQUEIRA, R. L. (2007). Revista Contabilidade \& Finanças USP: uma análise bibliométrica de 1999 a 2006. RIC: Revista de Informação Contábil, v. 1, n. 2, pp. 102-119. Disponível em: http://www.ufpe.br/ricontabeis/index.php/contabeis/article/viewFile/81/68. Acesso em: jan 2013.

LENCIONI, S. (2003). A emergência de um novo fato urbano de caráter metropolitano em São Paulo. A particularidade de seu conteúdo sócio-espacial, seus limites regionais e sua interpretação teórica. In: ENCONTRO NACIONAL DA ANPUR. Anais...

(2006a). "Reconhecendo metrópoles: território e sociedade". In: SILVA, C. A.; FREIRE, D. G. e OLIVEIRA, F. J. G. (orgs.). Metrópole: governo, sociedade e território. Rio de Janeiro, DP\&A/Faperj.

(2006b). "Da cidade e sua região à cidade-região". In: LIMA, L. C.; ELIAS, D. e SILVA, J. B. da (orgs.). Panorama da Geografia Brasileira I. São Paulo, Annablume.

LEROY, S. (2000). Sémanthiques de la métropolisation. L'espace geographique. Montpellier, Éditions Belin, v. 29, n. 1, pp. 78-89.

MAGALHÃES, F. (2008). Transformações socioespaciais na cidade-região em formação: a economia geopolítica do novo arranjo espacial metropolitano. Dissertação de Mestrado. Belo Horizonte, Universidade Federal de Minas Gerais.

MATOS, R. (2005). Periferias de grandes cidades e movimentos populacionais. Cadernos Metrópole, n. 13, pp. 71-105.

MENDOZA, F. R. (2016). La gentrificación en los estudios urbanos: una exploración sobre la producción académica de las ciudades. Cadernos Metrópole. São Paulo, v. 18, n. 37, pp. 697-719. Disponível em: http://cadernosmetropole.net/system/artigos/arquivos/000/000/361/original/3704. pdf?1478547563. Acesso em: dez 2017.

MOREIRA, A. M. L. (1989). Regiões Metropolitanas na Constituição Estadual. Adaptação do documento “O Município e a Questão Urbana. Sugestões para a Constituição do Estado de São Paulo". São Paulo, Fundação Prefeito Faria Lima.

MOURA, R. (2008). Arranjos urbano-regionais: uma categoria complexa na metropolização brasileira. Revista Brasileira de Estudos Urbanos e Regionais, v. 10, n. 2, pp. 29-49.

(2009). Arranjos urbano-regionais no Brasil: uma análise com foco em Curitiba. Tese de Doutorado. Paraná, Universidade Federal do Paraná.

MOURA, R.; LIBARDI, D. e BARION, M. I. (2006). Institucionalização de Regiões Metropolitanas: qual o sentido? Revista Paranaense de Desenvolvimento. Curitiba, n. 111, pp. 129-143. 
NÚÑEZ, A. e ROZE, J. (2014). Las palabras y las cosas en ciudad latinoamericana. Obstáculos epistemológicos en políticas urbanas argentinas. Cadernos Metrópole. São Paulo, v. 16, n. 31, pp. 61-88. Disponível em: http://cadernosmetropole.net/system/artigos/arquivos/000/000/282/original/ cm31_283.pdf?1474650659. Acesso em: dez 2017.

PÍREZ, P. (2005). Expansión territorial, privatización y fragmentación en la configuacion metropolitana de Buenos Aires. Cadernos Metrópole. São Paulo, n. 13, pp. 11-46. Disponível em: http://cadernosmetropole.net/system/artigos/arquivos/000/000/063/original/cm13_63. pdf?1474650642. Acesso em: nov 2011.

PRADILLA COBOS, E. (2009). Los territorios del neoliberalismo en América Latina. México, Universidad Autónoma Metropolitana, Unidad Xochimilco/Miguel Ángel Porrúa.

PRITCHARD, A. (1969). Statistical bibliography or bibliometrics? Journal of Documentation, v. 25, n. 4, pp. 348-349.

RIBEIRO, L. C. de Q. e BÓGUS, L. M. M. (1999). Apresentação. Cadernos Metrópole, São Paulo, n. 1, pp. 3-6. Disponível em: http://cadernosmetropole.net/system/edicoes/arquivos/000/000/002/ original/cm1.pdf?1474650637. Acesso em: jul 2011.

RIBEIRO, L. C. de Q. (org.) (2000). O futuro das metrópoles: desigualdades e governabilidade. Rio de Janeiro, Revan-Fase.

(coord.) (2004a). Relatório da Atividade 1a: Identificação dos espaços metropolitanos $e$ construção de tipologias. Rio de Janeiro, Observatório das Metrópoles/FASE/Ipardes (Projeto Análise das Regiões Metropolitanas do Brasil).

RIBEIRO, L. C. Q.; SILVA, E. T. e RODRIGUES, J. M. (2011). Metrópoles brasileiras: diversificação, concentração e dispersão. Revista Paranaense de Desenvolvimento. Curitiba, n. 120, pp. 171-201.

RIBEIRO, L. C. Q. et al. (2012). Níveis de integração dos municípios brasileiros em RMs, RIDEs e AUs à dinâmica da metropolização. Rio de Janeiro, Observatório das Metrópoles/UFRJ.

SANTOS, M. (1990). Metrópole corporativa fragmentada. O caso de São Paulo. São Paulo, Nobel.

SANTOS, T. V. dos (2017). Metropolização e diferenciações regionais: estruturas intraurbanas e dinâmicas metropolitanas em Belém e Manaus. Cadernos Metrópole. São Paulo, v. 19, n. 40, pp. 865-890. Disponível em: http://cadernosmetropole.net/system/artigos/arquivos/000/000/406/original/4008.pdf?1513012657. Acesso em: jan 2018.

SASSEN, S. (2007). El reposicionamiento de las ciudades y regiones urbanas en una economía global: ampliando las opciones de políticas y gobernanza. EURE. Santiago, v. 33, n. 100, pp. 9-34. Disponível em:https://scielo.conicyt.cl/pdf/eure/v33n100/art02.pdf. Acesso em: mar 2012.

SCHOUMAKER, J. M. (1998). “Metropolização - um dado novo?”. In: BARATA-SALGUEIRO, P. (coord.). Globalização e reestruturação urbana. Lisboa, Centro de Estudos Geográficos da Universidade de Lisboa.

SCOTT, A.; AGNEW, J.; SOJA, E. e STORPER, M. (2001). Cidades-regiões globais. Espaço e Debates: Aliança e competição entre cidades. São Paulo, n. 41, pp. 11-25.

SILVA, M. R. (2004). Análise bibliométrica da produção científica docente do Programa de PósGraduação em Educação Especial / UFSCar: 1998-2003. Dissertação de Mestrado. São Carlos, Universidade Federal de São Carlos. 
SILVA, K. A. A. da; CUNHA, J. M. P. da e ORTEGA, G. M. (2017). Um olhar demográfico sobre a constituição da macrometrópole paulista: fluxos populacionais, integração e complementaridade. Cadernos Metrópole. São Paulo, v. 19, n. 40, pp. 721-748. Disponível em: http://cadernosmetropole.net/ system/artigos/arquivos/000/000/400/original/4002.pdf?1513011474. Acesso em: jan 2018.

SILVEIRA, L. S. e MUNIZ, J. O. (2014). Variações intra e intermetropolitanas da desigualdade de renda racial. Cadernos Metrópole. São Paulo, v. 16, n. 31, pp. 263-287. Disponível em: http://cadernosmetropole.net/system/artigos/arquivos/000/000/292/original/cm31_293. pdf?1474650659. Acesso em: fev 2016.

SOJA, E. (2000). Postmetropolis: critical studies of cities and regions. Oxford, Blackwell Publishing.

(2013). Para além de postmetropolis. Revista UFMG. Belo Horizonte, v. 20, n. 1, pp. 136-167.

SOUZA, J. de e TERRA, D. C. T. (2017). Rio de Janeiro: rumo a uma nova região metropolitana? Cadernos Metrópole. São Paulo, v. 19, n. 40, pp. 817-840. Disponível em: http://cadernosmetropole.net/ system/artigos/arquivos/000/000/404/original/4006.pdf?1513012357. Acesso em: jan 2018.

TAYLOR, P. (1995). World cities in a world-system. Cambridge, Cambridge University Press.

ULTRAMARI, C.; FIRMINO, R. J. e SILVA, S. F. P. (2011). Uma abordagem bibliométrica do estudo do Planejamento Urbano no Brasil nas décadas de 1990 e 2000. In: XIV Encontro Nacional da ANPUR. Anais. Rio de Janeiro/RJ.

VELTZ, P. (1996). Mondialization. Villes et territories. L'economie de d'archipel. Paris, Presses Universitaires de France.

VÉRAS, M. P. B. (1999). Territorialidade e cidadania em tempos globais: imigrantes em São Paulo. Cadernos Metrópole. São Paulo, n. 2, pp. 73-119. Disponível em: http://cadernosmetropole.net/ system/artigos/arquivos/000/000/006/original/cm2_6.pdf?1474650637. Acesso em: out 2011.

VILLAÇA, F. (1998). Espaço intra-urbano no Brasil. São Paulo, Studio Nobel; Fundação de Amparo à Pesquisa no Estado de São Paulo.

Texto recebido em 12/jun/2018 Texto aprovado em 21/set/2018 
